Marquette University

e-Publications@Marquette

School of Dentistry Faculty Research and

Publications

Dentistry, School of

$1-2018$

Survival Rates of Stainless Steel Crowns and Multi-Surface Composite Restorations Placed by Dental Students in a Pediatric Clinic

Badia A. Zahdan

Aniko Szabo

Cesar Gonzalez

Elaye Okunseri

Christopher Okunseri

Follow this and additional works at: https://epublications.marquette.edu/dentistry_fac

Part of the Dentistry Commons 


\title{
Survival Rates of Stainless Steel Crowns and Multi-Surface Composite Restorations Placed by Dental Students in a Pediatric Clinic
}

\author{
Badia A Zahdan */Aniko Szabo **/Cesar D Gonzalez***/Elaye M Okunseri ****/ Christopher E \\ Okunseri $* * * * *$
}

Purpose: This study examined survival rates of multi-surface composite restorations and stainless steel crowns (SSCS) placed by students in a pediatric dental clinic as well as the length of time it takes for restorations to be replaced with stainless steel crowns. Study design: Data from electronic dental records for all children with at least one 2-surface composite restorations or SSCs on a primary first or second molar from January 1, 2007 to September 30, 2015 were analyzed. The primary outcome was the time to a new restoration or SSC on the same tooth, with time to a crown as a secondary outcome. Descriptive statistics were obtained and the cumulative incidence of the event of interest was estimated using $95 \%$ confidence intervals and compared between groups using Fine-Gray regression. Results: A total of 6,288 teeth from 2,044 children were analyzed. Three years after the initial procedure, $1.5 \%$ of SSCs and $21 \%$ of 2 and 3 surface composite restorations failed and needed a replacement (Hazard Ratio [HR] $=14 ; 95 \%$ Confidence interval [CI] 9-22, $p<0.001)$. Also, 6.8\% of composite restorations needed replacement with SSCs' $(H R=4$; 95\% CI: 3-7). Conclusions: The study demonstrates that stainless steel crowns had a higher survival rate than multi-surface composite resins placed by students at a pediatric dental clinic in primary molars of children.

Key words: Children, stainless steel crowns, survival rates and composite restoration

*Badia A Zahdan BS, Department of Developmental Sciences, Marquette University School of Dentistry, Wisconsin.

**Aniko Szabo PhD, Institute of Health and Society, Medical College of Wisconsin, Milwaukee, Wisconsin.

***Cesar D. Gonzalez DDS, MS, Department of Developmental Sciences, Marquette University School of Dentistry, Wisconsin.

****Elaye M Okunseri, MBA, MSHR, Department of Clinical Services, Marquette University School of Dentistry, Milwaukee, Wisconsin. *****Christopher E Okunseri, BDS, MSc, Department of Clinical Services, Marquette University School of Dentistry, Milwaukee, Wisconsin.

Send all correspondence to:

Christopher Okunseri.

Room 356,

Marquette University School of Dentistry,

P.O. Box 1881 Milwaukee, Wisconsin. 53201-1881

Phone: (414) 288-6524

E-mail: christopher.okunseri@marquette.edu

\section{INTRODUCTION}

$\mathrm{G}$ lobally, dental training institutions spend a number of didactic and clinical hours in their curriculum training dental students' on how and when to use different preventive measures and restorative materials for dental caries management. In addition, there is increased emphasis on evidence-based care in the management of most dental conditions. However, dental caries remains one of the most prevalent chronic childhood diseases. When dental caries is left untreated, it can lead to poor growth, loss of school time and reduced self-esteem. ${ }^{1,2}$ The severity and impact of dental caries is most pronounced at the tooth level when it affects many teeth and multiple surfaces. Treatment decisions regarding how to restore multiple surfaces affected by caries and what materials to use depend on many factors such as patient's age, medical status, reimbursement, clinicians' comfort level and expertise, assessment of patient's ability to cooperate and tolerate treatment, parents' attitudes/beliefs, and the value attributed to oral health. ${ }^{3}$

Henzi et al documented that the skills and techniques acquired by students in their clinical education are associated with their interaction with the faculty who serve as their coaches, mentors and evaluators. ${ }^{4}$ This interaction between students and faculty tend to define how students will practice dentistry when they graduate from school. In addition, advances in technology and research combined with an 
improved understanding of the pathophysiology of dental caries will lead to some changes in the indications and use of various dental materials and techniques for the treatment of multi-surface carious teeth over the years. Despite these widely understood facts by many dental school faculty, there is limited research on dental students' exposure to various types of restorative procedures available for the management of dental caries under the supervision of dental school faculty.

Donly and Godoy recommended that resin-based composites be used for restoring primary molars that extend beyond the proximal line angles. ${ }^{5}$ Sue and Randall concluded that SSCs are still superior in durability and longevity when compared to Class II amalgam or resin-based restorations in primary teeth. ${ }^{6}$ Despite the availability of this information, little is known about the survival rates of stainless steel crowns and multi-surface composite resin restorations provided in dental school settings under the supervision of faculty. This is important given that dental students are more likely to use materials and procedures they were taught and exposed to in dental school in their private practices. In addition, the dental students do not place amalgam restorations at the pediatric clinic in our study. Therefore, this study examined survival rates of multi-surface composite resin restorations and stainless steel crowns (the two procedures used by students at this particular dental school), as well as the length of time it takes for restorations to be replaced with stainless steel crowns. We hypothesized that multi-surface composite restorations would have lower survival rates compared to stainless steel crowns when placed by students.

\section{MATERIALS AND METHOD}

The study data was extracted from the electronic patient management database-AxiUm available at the Marquette University School of Dentistry in Milwaukee, Wisconsin. All records for children aged 2-12 years with multiple surface composite restorations and stainless steel crowns seen at the undergraduate pediatric clinic from January $1^{\text {st }}, 2007$ to September 30th, 2015 were extracted from AxiUm. The records included in the analysis were for those children treated without sedation by a dental student and supervised by faculty. Patients with recall visits and those with complete records were included in the data analyzed. Patients treated with pulp therapy were excluded and students provided treatment to all patients based on a standard protocol in the school that includes the use of a rubber dam for all cases. Restorations are typically not sealed and patients with initial 1 surface lesions were not included in our dataset.

Other available variables in AxiUm included in our analysis were: date of service, patient age, gender, race/ethnicity, insurance type and poverty status, treatment type on primary first or second molar. The primary outcome measure was the time between the first restoration and a new restoration or a $\mathrm{SSC}$, i. e. time to restoration failure. Time to a subsequent SCC was considered as a secondary outcome. Marquette University's Institutional Review Board approved the study as expedited.

\section{Statistical Analysis}

Descriptive statistics were calculated at both the patient level (treating each patient as a unit of observation) and the tooth level (treating each tooth as a unit of observation), all other analyses were performed at the tooth level. The first recorded restoration with two or more surfaces or a SSC was considered the index visit. Teeth without a new restoration or SCC were censored at the patient's last clinical visit. Exfoliation of primary teeth is a competing risk for filling failure and is not recorded in the medical record, so a random uniformly distributed time was attributed to each patient based on the American Dental Association (ADA) tables of tooth eruption/ exfoliation (age 9-11 for first primary molars and 10-12 for second primary molars). Cumulative incidence of treatment failure was estimated using $95 \%$ confidence intervals with loss of the tooth as a competing risk. Groups were compared using Fine-Gray regression.

\section{RESULTS}

A total of 2,044 unique children with 6,288 teeth were included in this analysis. Table 1a presents descriptive statistics of the study population at the patient level. About $51 \%$ were female, $45 \%$ Hispanics and $97 \%$ were from households with annual incomes below $\$ 25,180$. The average number of primary molars with composites or crowns in each patient was 3.0, with the least being 1 and the highest 8 .

Tooth level summary statistics are presented in Table 1b. About $61 \%$ of the total restorations in the teeth were composite resins. The comparison of stainless steel crowns

Table 1a: Descriptive Statistics-Patient Level

\begin{tabular}{lc}
\hline \multicolumn{1}{c}{ Variables } & All N=2044 \\
\hline Gender & $\mathrm{N}(\%)$ \\
Female & $992(48.8)$ \\
Male & $1041(51.2)$ \\
Unknown & 11 \\
Race/Ethnicity & \\
White & $350(19.4)$ \\
African-American & $539(28.3)$ \\
Hispanic & $850(44.6)$ \\
American Indian & $3(.002)$ \\
Asian & $41(2.2)$ \\
Other & $121(6.4)$ \\
Missing & 140 \\
Poverty Level & \\
A $^{T}$ & $64(3.4)$ \\
$B^{P}$ & $1796(96.6)$ \\
Missing & 184 \\
Number of Primary Molars with a Composite resin/SS Crown \\
Mean \pm SD & $3.0 \pm 2.0$ \\
Median (min-max) & $2(1-8)$ \\
\hline 'Household of 3-Annual income above $\$ 25,180$ & \\
${ }^{P}$ Household of 3-Annual income below $\$ 25,180$ & \\
&
\end{tabular}


Table 1b: Descriptive Statistics-Tooth Level

\begin{tabular}{|c|c|c|c|c|}
\hline Variables & $\begin{array}{c}\text { Total } \\
\mathrm{N}=6228(\%)\end{array}$ & $\begin{array}{c}\text { Crown } \\
\mathrm{N}=\mathbf{2 4 4 4}(\%)\end{array}$ & $\begin{array}{l}\text { Composite resin } \\
\quad \mathrm{N}=3784(\%)\end{array}$ & P Value \\
\hline Gender & & & & $0.850^{c}$ \\
\hline Female & 2908 (46.9) & $1138(46.8)$ & $1770(47.0)$ & \\
\hline Male & $3292(53.1)$ & $1296(53.2)$ & $1996(53.0)$ & \\
\hline Missing & 28 & 10 & 18 & \\
\hline Race/Ethnicity & & & & $<.001^{\mathrm{C}}$ \\
\hline African American & $1450(25.0)$ & $645(28.1)$ & $805(23.0)$ & \\
\hline American Indian & $3(0.1)$ & $1(0.0)$ & $2(0.1)$ & \\
\hline Asian & $161(2.8)$ & $96(4.2)$ & $65(1.9)$ & \\
\hline White & $1083(18.7)$ & $442(19.3)$ & $641(18.3)$ & \\
\hline Hispanic & $2692(46.4)$ & $916(39.9)$ & $1776(50.6)$ & \\
\hline Other & $412(7.1)$ & $194(8.5)$ & $218(6.2)$ & \\
\hline Missing & 427 & 150 & 277 & \\
\hline Poverty Level & & & & $0.013^{c}$ \\
\hline A & $174(3.1)$ & $54(2.4)$ & $120(3.5)$ & \\
\hline B & $5500(96.9)$ & $2224(97.6)$ & $3276(96.5)$ & \\
\hline Missing & 554 & 166 & 388 & \\
\hline Tooth & & & & $<.001^{\mathrm{C}}$ \\
\hline $\begin{array}{l}\text { A-Right maxillary primary } \\
\text { 2nd molar }\end{array}$ & $737(11.8)$ & $191(7.8)$ & $546(14.4)$ & \\
\hline $\begin{array}{l}\text { B-Right maxillary primary } 1^{\text {st }} \\
\text { molar }\end{array}$ & $723(11.6)$ & $238(9.7)$ & $485(12.8)$ & \\
\hline $\begin{array}{l}\text { I-Left maxillary primary } 1^{\text {st }} \\
\text { molar }\end{array}$ & $659(10.6)$ & $231(9.5)$ & $428(11.3)$ & \\
\hline $\mathbf{J}$ - Left maxillary 2nd molar & $703(11.3)$ & $188(7.7)$ & $515(13.6)$ & \\
\hline $\begin{array}{l}\text { K- Left mandibular primary } \\
2^{\text {nd }} \text { molar }\end{array}$ & 765 (12.3) & $381(15.6)$ & $384(10.1)$ & \\
\hline $\begin{array}{l}\text { L-Left mandibular primary } \\
1^{\text {st }} \text { molar }\end{array}$ & $919(14.8)$ & $420(17.2)$ & $499(13.2)$ & \\
\hline $\begin{array}{l}\text { S- Right mandibular primary } \\
\text { 1st molar }\end{array}$ & $938(15.1)$ & $419(17.1)$ & $519(13.7)$ & \\
\hline $\begin{array}{l}\text { T- Right mandibular primary } \\
2^{\text {nd }} \text { molar }\end{array}$ & $784(12.6)$ & $376(15.4)$ & $408(10.8)$ & \\
\hline Age at index procedure & & & & $<.001^{\top}$ \\
\hline Mean \pm SD & $6.0 \pm 1.5$ & $5.7 \pm 1.5$ & $6.2 \pm 1.5$ & \\
\hline Median (min-max) & $5.8(1.9-11.8)$ & $5.5(1.9-11.8)$ & $6.1(2.0-11.4)$ & \\
\hline \multicolumn{5}{|l|}{ Index procedure } \\
\hline $\begin{array}{l}\text { Prefab SS crown - primary } \\
\text { Tooth }\end{array}$ & $2444(39.2)$ & $2444(100.0)$ & $0(0.0)$ & \\
\hline $\begin{array}{l}\text { Resin-based comp-2 surf, } \\
\text { post. }\end{array}$ & $3575(57.4)$ & $0(0.0)$ & $3575(94.5)$ & \\
\hline $\begin{array}{l}\text { Resin-based comp-3 surf, } \\
\text { post. }\end{array}$ & $205(3.3)$ & $0(0.0)$ & $205(5.4)$ & \\
\hline $\begin{array}{l}\text { Resin-based comp-4+surf, } \\
\text { post. }\end{array}$ & $4(0.1)$ & $0(0.0)$ & $4(0.1)$ & \\
\hline Number of procedures & & & & $<.001^{\top}$ \\
\hline Mean \pm SD & $1.1 \pm 0.3$ & $1.0 \pm 0.1$ & $1.1 \pm 0.3$ & \\
\hline Median (min-max) & $1.0(1.0-4.0)$ & $1.0(1.0-3.0)$ & $1.0(1.0-4.0)$ & \\
\hline
\end{tabular}

Tt-test; Chi-square test; Wilcoxon rank-sum test 
and composite resins by gender was not statistically significant. The difference by race/ethnicity was statistically significant, Hispanics were over-represented among the teeth with composite resins (50\% vs $40 \%$ of those with crowns), while African Americans were overrepresented among the teeth with stainless steel crowns ( $28 \%$ vs $23 \%$ of those with composite resins). In terms of teeth with restorations, mandibular teeth were overrepresented among stainless steel crowns (15\% to $17 \%$ for left mandibular primary $1^{\text {st }}$ and $2^{\text {nd }}$ molars $\{K, L\}$, right mandibular primary $1^{\text {st }}$ and $2^{\text {nd }}$ molars $\left.\{\mathrm{S}, \mathrm{T}\}\right)$, while among composite resins the teeth distribution was more uniform $(13 \%$ to $14 \%$ for maxillary right and left primary $2^{\text {nd }}$ molars $\{A$, $\mathrm{J}\}$ mandibular right and left $1^{\text {st }}$ primary molars $\left.\{\mathrm{L}, \mathrm{S}\}\right)$. The average age for teeth with stainless steel crown and composite resin was similar at about $6 \pm 2$ years. Almost $95 \%$ of the composite restorations were 2 -surface fillings.

When combining all composite restoration groups at a 3 year follow-up, 1.5\% (95\% CI: $0.9 \%-2.6 \%)$ of stainless steel crowns and $21 \%$ (95\% CI: 19\%-23\%) of composite restorations failed and needed to be replaced with either another SSC or a resin. About $6.8 \%$ (95\% CI: $5.6 \%-8.3 \%)$ of the original composite restorations were replaced by a SSC. The figure describes the cumulative incidences of failure (i. e., new restoration or replacement by a stainless steel crown) and of replacement by a stainless steel crown of an initial stainless steel crown, 2-surface composite resin and 3 surface composite. At a 3-year follow-up, the failure rate for stainless steel crowns was the lowest and that of 3 surface composite resins was highest for both outcomes.

Figure 1: Cumulative incidence of Replacement of Stainless Steel Crowns, 2-Surface Composite Resin, and 3+ Surface Composite Resin with a New Composite Filling or Stainless Steel Crown (Left Panel) or a Stainless steel Crown (right panel).
Table 2 presents the results from the Fine-Gray regression model for the cumulative incidence of failure and replacement by stainless steel crown by type of index procedure. The comparison of 2 and $3+$ surface composite resin in terms of time to replacement with stainless steel crowns and time to restoration failure was not statistically significant. Two (2) and $3+$ surface composite resin had $4 \mathrm{X}$ and $6 \mathrm{X}$ higher failure rate for time to replacement with stainless steel crowns (combined hazard ratio $\mathrm{HR}=4$; 95\% $\mathrm{CI}$ : 3-7). Additionally, 2 and $3+$ surface composite resin had $14 \mathrm{X}$ and $17 \mathrm{X}$ higher failure rate for time to replacement with another composite filling and both were statistically significant (combined HR= 14; 95\% CI 9- 22, $\mathrm{p}<0.001)$. No differences in failure rates were found between the teeth $(\mathrm{p}=0.69$, data not shown).

Table 2: Results of Fine-Gray Regression Model for the Cumulative Incidence of Restoration Failure by Type of Index Procedure

\begin{tabular}{|c|c|c|c|c|}
\hline \multirow[b]{2}{*}{ Comparison } & \multicolumn{2}{|c|}{ Time to crown } & \multicolumn{2}{|c|}{ Time to failure } \\
\hline & $\begin{array}{c}\text { Hazard } \\
\text { ratio }\end{array}$ & $\begin{array}{c}95 \% \\
\text { Confidence } \\
\text { Interval }\end{array}$ & $\begin{array}{c}\text { Hazard } \\
\text { ratio }\end{array}$ & $\begin{array}{c}95 \% \\
\text { Confidence } \\
\text { Interval }\end{array}$ \\
\hline $\begin{array}{l}2 \text { surface } \\
\text { composite resin } \\
\text { Vs. } 3+ \\
\text { composite } \\
\text { resins }\end{array}$ & 0.67 & $0.35-1.27$ & 0.79 & $0.53-1.18$ \\
\hline $\begin{array}{l}\text { 2-surface } \\
\text { composite resin } \\
\text { vs. stainless } \\
\text { steel crown }\end{array}$ & 4.04 & $2.46-6.66$ & 13.7 & $8.5-22.0$ \\
\hline $\begin{array}{l}3+\text { surface } \\
\text { composite resin } \\
\text { vs. stainless } \\
\text { steel crown }\end{array}$ & 6.05 & $2.80-13.06$ & 17.3 & $9.5-31.7$ \\
\hline
\end{tabular}

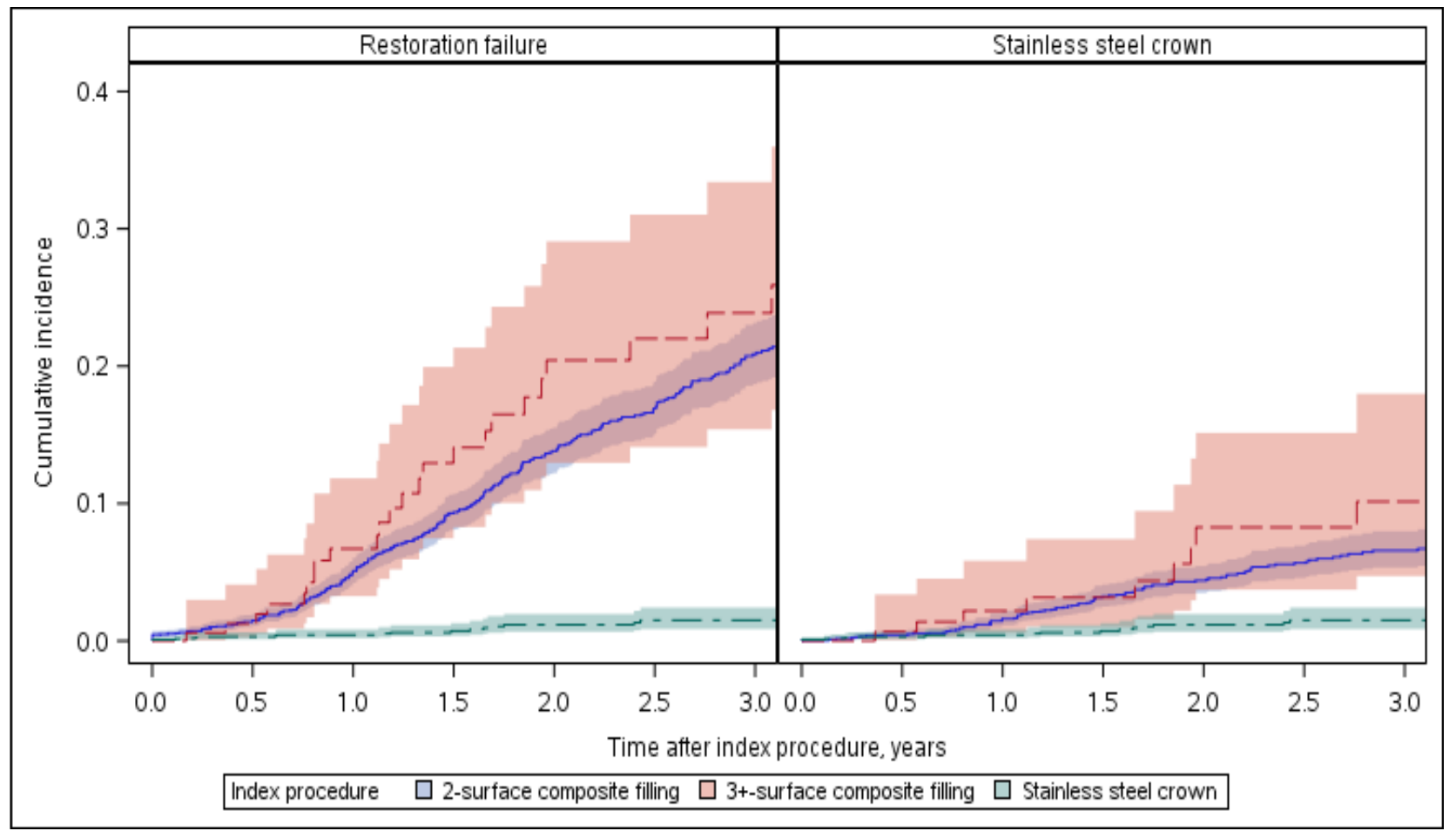

Shaded areas represent pointwise 95\% confidence bands. 


\section{DISCUSSION}

This study highlights the importance of stainless steel crowns and multi-surface composite restorations in the management of primary teeth affected by multi-surface caries. Stainless steel crowns had higher survival rates than multi-surface composite restorations in this study. To the best of our knowledge, there are no previous studies on the survival rates of SSC and multi-surface composite restoration placed by dental students. However, our finding is closely related to previous studies that have attempted to compare SSCs and amalgam restorations. ${ }^{7-9}$ Einwag and Dunninger reported that SSCs have higher longevity compared to amalgam restorations and indicated that they are an acceptable alternative for the treatment of multi-surface caries in primary teeth. ${ }^{7}$ In addition, Eidelman et al demonstrated improved outcomes of treatments in all parameters measured with SSCs placed under general anesthesia for the treatment of caries..$^{10}$ Our findings expand the literature that supports the use of SSCs for treatment of teeth affected by multi-surface caries where possible, instead of composite restoration, especially when survival rate of treatment is of concern to the clinician.

We found that about twenty-one percent of multi-surface composite restorations failed and needed to be replaced with either another composite restoration or SSC, if the teeth were not extracted. This finding clearly reinforces the idea that the best replacement for a failed resin restoration for primary teeth is a stainless steel crown. Bohaty stated that amongst children who received either a multi-surface composite restoration or amalgam, composite restorations had a fifty percent chance of re-treatment as compared to the multi-surface amalgam restorations. ${ }^{11}$ Additionally, Bohaty compared the mean lifespan of failed amalgams and composite restorations and concluded that amalgam restorations failed at around 11 years, while composite restorations failed significantly faster-at around 6 years. ${ }^{11}$ Drummond reported that at two years' follow up, amalgam had a survival rate of $57 \%$, composite $73 \%$, compomer $85 \%$, and stainless steel crowns $93 \%$ in children at high risk for caries. ${ }^{12}$ Stainless steel crowns are considered to be less prone to recurrent caries because when placed correctly over teeth, they seal the teeth from the rest of the mouth. ${ }^{10,12,13}$ In contrast, multi-surface resins and amalgam restorations expose some of the tooth margins, thus rendering the teeth more prone to recurrent caries and failure of the restoration. ${ }^{14}$

Another important finding was the fact that two or more surface composite restorations had a much higher chance of failure and being replaced with an SSC as compared to a SSC being replaced with another SSC. This finding is consistent with that of another study, which showed that at four years, $68 \%$ of SSCs survived and only $40 \%$ of composite restorations did not need to be replaced. ${ }^{15}$ One possible explanation for why composite resins fail is the fact that with time, more pressure is placed on a restored tooth leading to a higher chance of the restorations becoming weak and prone to failure. Derkson et al suggested that the failure of composites compared to amalgams was mainly due to occlusal wear, therefore for larger lesions, composite restorations are usually not recommended. ${ }^{16}$ In addition, composite resins wear at around 50 micrometers a year and tend to wear at a higher rate compared to other restorations. ${ }^{16}$ Furthermore, composite restorations do not protect the whole tooth, thus they have a higher chance of fracturing and ultimately failing as compared to SSCs. ${ }^{16}$

Based on our study findings, we believe that the age at which a child receives a restoration is critical to the decision-making process about the type of restoration required for multi-surface caries by practitioners. The use of professional judgment combined with a determination of patients' caries risk is also important in determining the benefit of SSCs, so as to save the patient, parent and operator not only time, but money as well. For example, a three-year-old child with a large carious lesion on a primary first molar will receive a SSC, while a ten-year-old child with the same lesion may receive a multi-surface composite restoration. In difficult situations, faculty typically recommend that students place SSCs since the procedure is less technique-sensitive and the outcome would not be as detrimental if, for instance saliva were to contaminate the working area, compared to a multi-surface composite restoration. ${ }^{17,18}$

This study revealed some important findings. However, it is important to note the following limitations. First, the study data was extracted from a single dental training institution, which could make the data prone to selection bias and coding errors. Second, our findings are not generalizable beyond the study sample and other similar-type institutions with the same training philosophy. Third, the treatment for the multi-surface caries was provided by different students with different levels of competency. Also, the fact that treatments were done by students and not dentists may have skewed our findings. Nonetheless, the students were all supervised by faculty who ensure that standards of care are maintained at all times. In addition, investigators were unable to determine the age of the child when they received their first restoration, and the time to failure and replacement are possible confounders. Finally, there was no individual-level data on exfoliation of teeth which is a competing factor with restoration failure.

\section{CONCLUSION}

In this study, stainless steel crowns placed by students at a dental training institution had a higher survival rate when compared to multi-surface composite resin restorations. 


\section{REFERENCES}

1. Çolak H, Dülgergil CT, Dalli M, Hamidi MM. Early childhood caries update: A review of causes, diagnoses, and treatments. J Nat Sci Biol Med 4(1): 29-38, 2013

2. US Department of Health and Human Services. Oral Health in America: A Report of the Surgeon General-Executive Summary . Rockville, MD: US Department of Health and Human Services, National Institute of Dental and Craniofacial Research, National Institutes of Health, 2000.

3. Seow WK. Biological mechanisms of early childhood caries. Community Dent Oral Epidemiology 26 (supplement 1): 8-18, 1998.

4. Henzi D, Davis E, Jasinevicius R. North American Dental students' Perspectives about Their Clinical Education. J. Dent. Educ 70(4): 361-377, 2006.

5. Donly KJ, Garcias-Godoy F. The use of resin-based composites in children: an update. Pediatr Dent 37: 136-143, 2015.

6. Seale NS, Randall R. The use of stainless steel crowns: a systematic literature review. Pediatr Dent 37: 147-162, 2015.

7. Einwag J, Dunninger P. Stainless steel crown versus multisurface amalgam restorations: an 8-year longitudinal clinical study. Quintessence Int 27(5): 321-323, 1996.

8. Messer LB, Levering NJ. The durability of primary molar restorations: II. Observations and predictions of success of stainless steel crowns. Pediatr Dent 10: 81-85, 1988.

9. Levering NJ, Messer LB. The durability of primary molar restorations: I. Observations and predictions of success of amalgams. Pediatr Dent 10: 74-80, 1988.

10. Eidelman E1, Faibis S, Peretz B.A comparison of restorations for children with early childhood caries treated under general anesthesia or conscious sedation. Pediatr Dent 22(1): 33-37, 2000.
11. Bohaty BS, Ye Q, Misra A, Sene F, Spencer P. Posterior composite restoration update: focus on factors influencing form and function. Clinical, Cosmetic and Investigational Dentistry 5: 33-42, 2013.

12. Drummond BK, Davidson LE, Williams SM, Moffat SM, Yers KM. Outcomes two, three and four years after comprehensive care under general anesthesia. NZ Dent J 2:32-37, 2004.

13. Fuks AB, Ram D, Eidelman E. Clinical performance of esthetic posterior crowns in primary molars: a pilot study. Pediatr Dent 21 (7): 445-448, 1999.

14. Milsom KM, Kearney-Mitchell PI, Shahid S, Threlfall A, Blinkhorn A, Tickle M. The treatment of primary molar teeth presenting with two surface caries: a review of care delivered by the Personal Dental Services in Bradford. Int J Health Promo Educ 44: 141-144, 2006.

15. Papathanasiou AG, Curzon MEJ, Fairpo CG. The influence of restorative material on the survival rate of restorations in primary molar. Pediatr Dent 16: 282-288, 1994

16. Derkson GD, Richardson AS, Waldman R: Clinical evaluation of composite resin and amalgam posterior restorations: three year results. J Can Dent Assoc 50: 478-480, 1984.

17. Deprá MB, de Almeida JX, da Cunha Tde M, Lon LF, Retamoso LB, et al. Effect of saliva contamination on bond strength with a hydrophilic composite resin. Dental Press J Orthod 18(1): 63-68, 2013.

18. Furuse AY, Fernandes Da Cunha L, Benetti AR. et al. Bond Strength Of Resin-Resin Interfaces Contaminated With Saliva And Submitted To Different Surface Treatments. J Appl Oral Sci 15(6): 501-505, 2007. 